work with normal and malignant cells of identical tissue origin has clearly shown that thermosensitivity is one of the early characteristics of the malignant cell transformation. ${ }^{2}$

A paper, not cited by $\mathrm{Mr}$. Hall and his colleagues, on the relationship of hyperthermia and radiation in the treatment of bladder cancer was published by Cockett et al. in $1967 . .^{3}$ Though heat alone can cure cancer in a few experimental systems ${ }^{4}$ many of the published papers report investigations into the use of heat as a "sensitizer" to radiation $^{6-8}$ or chemotherapic agents. ${ }^{9-11}$ Unpublished in vitro data of my own show that a temperature of $42^{\circ} \mathrm{C}$ applied for two hours enhances the killing effect of several chemotherapic agents by factors varying from 10 to 100 . - I am, etc.,

I. HAR-KEDAR

Academic Department of Radiotherapy

Middlesex Hospital Medical School,

London $W .1$

1 G:ovanella, B. C., et al., Cancer Research, 1973, 33, 2568.

Chen, T. T., and Heidelberger, C., International Fournal of Ċancer, 1969, 4, 166.

Cockett, A. T. K., et al., fournal of Urology, $1967,97,1034$

Overgaard, K., and Overgaard, J., European Fournal of Cancer, 1972. 8, 65.

5 Cavaliere, R., et al., Cancer, 1967. 20. 1351.

Crile, G., jun., Cancer Research, 1963, 23, 372.

of Medical Sciences

Cater, D. B., Silver, I. A and Watkinson, D A. Acta Radiologica. Therapy, Physics and Biology,

$1964,2.321$.
9 Stehlin. J. S., Surgery, Gynecology and Obstetrics, 1969, 129. 305.

10 Johnson, H. A., and Pavelec, M., fournal of the National Cancer Institute. 1973, 50, 903.

\section{Strongyloidiasis in Britain}

SIR,-Brigadier J. Mackay-Dick (18 May, p. 389) draws attention to this scourge as affecting some of those who served in the Far East in the second world war. One may add that the possibility of this parasitic infection should also be kept in mind in expatriates living in Britain. Indeed, as has been stated quite recently, "no immigrant from an endemic area should be treated with corticosteroids or other immunosuppressives until the stools have been examined. ${ }^{2}$ - I am, etc.,

\section{Wally Vella}

Department of Pathology,

Royal Army Medical College,

London S.W.1

1 Royle, G., Fraser-Moodie, A., and WansbroughJones. M., British fournal of Surgery, 1974 2 Poltera, A. A., Annals of Tropical Medicine and Parasitology, 1974, 68, 81 .

\section{Acute Respiratory Failure in Muslim} Babies

SIR,-On three occasions in the last two years Pakistani babies have been sent to accident departments in this city extremely ill, with feeble, shallow breathing. In only one case was the cause of the illness known to the staff of the accident department on arrival: all had had an overdose of Nepenthe before circumcicion in a local doctor's surgery. One child needed prolonged artificial ventilation and another had several fits, presumably due to anoxia.

Nepenthe would seem a very unsuitable drug for this purpose. Most standard books recommend that opiates should not be used for young babies. The smallest dose of Nepenthe that can be measured with reason- able accuracy, even with an insulin syringe, is one minim $(0.06 \mathrm{ml})$, and this is the dose recommended for a 1-year-old child. This condition should be borne in mind by the staff of casualty departments in cities with large Muslim communities.-I am, etc.,

\section{E. M. CARR-SAUNDERS}

East Birmingham Hospital,

Birmingham

\section{Resuscitation for Students}

SIR,-With reference to your leading article (23 March, p. 530), in hospitals there is usually no shortage of emergenciesaccidents, cardiac arrest, overdose, postoperative collapse, and severe infections and burns. These patients need varying degrees of resuscitation advancing to intubation, central venous pressure monitoring, and careful as-essment of urinary flow as well as the all-important total assessment and clinical supervision. Almost all these techniques can be learnt in a 6-10-week term of anaesthetics by first- and second-year graduates. Under graduates (and others) fail to appreciate the importance of this term, but either by word of mouth or from the simple observation that those who have "done" anaesthetics are just so much more competent in the emergency, the early graduates have learned to demand such a term.

Because of a universal reauest, in our hospital we have cut the time in anaesthetics to five weeks, but from the second day the junior helps decide the drugs and mixes and iniects and intubates. It is just no good a all if he simply sits at the feet of the great man. Thirty intubations a week for 5-10 weeks gives a lot of confidence. With this and his casualty experience-particularly night casualty - an average second-year graduate is more than capable of handling a severe chest or head iniury with drip, tube, catheter, and chest drainage.

For the rest of the year the iunior graduate spends set periods in medicine, surgery, casualty, and the other disciplines-that is, eye, E.N.T., psychiatry, obstetrics, etc. At various times during this period he would be dealing with emergencies either in the ward, in casualty, or in the intensive care unit To an Australian graduate it seems incredible that in Britain only two or three of the major divisions of medicine are practised by the junior before his final decision to enter a special field. It is hard for us to imagine how people could practice everyday medicine either in a specialized unit or in general practice without having some personal experience in orthopaedics, paediatrics, psychiatry, and even possibly medicine or surgery. In this respect the most valuable of all is anaesthetics, as it gives a first-hand knowledge of human physiology and with it a sense of clinical security-particularly in case of emergencies. - I am, etc.,

Toowoomba General Hospital
Toowoomba, Queensland

\section{A. O'ROURKE}

\section{Certificate of Contraindication to Smallpox Vaccination}

SIR,-If a traveller cannot be vaccinated against smallpox for medical reasons it is a great help to all concerned if his doctor issues a brief "certificate of contraindication" stating this. No lengthy medical details are required and provided the traveller visits only those countries where smallpox is endemic the note can protect him from long delays at port health control stations. But should the traveller visit a smallpox-infected area his position is very difficult. Not only does he risk catching smallpox but on returning to this country he may be faced by the prospect of 14 days in an isolation hospital, which costs the traveller time and the country money, and causes much annoyance and distress.

Working at the Health Control Unit at Heathrow Airport I meet many passengers just arrived from infected areas to whom isolation comes as a complete surprise. They fondly imagine their "certificate of contraindication" substitutes for a valid Internation Certificate of Vaccination against smallpox and is all that is required. The travellers or their parents have not been told of the risks involved. So may I appeal to all doctors to draw a careful distinction between endemic and infected areas when advising on travel requirements, particularly if their patients intend visiting India, Nepal, Pakistan, Bangladesh, Ethiopia, or the French Territory of the Afars and the Issas? Up-to-date information on smallpox prevalence is printed in the Weekly Epidemiological Record of the World Health Organization or may be obtained by phoning the Health Control Unit at Heathrow. Until smallpox has been entirely eradicated, vaccination supported by a valid International Certificate of Vaccination will remain the safest course for travellers abroad and will ensure they end their holiday having enjoyed themselves instead of languishing in an infectious diseases hospital for an extra fortnight.-I am, etc.

Michael J. James

Heathrow Airport,

Hounclow, Middlesex

\section{Simulated Patients}

SIR,-In your leading article (25 May, D. 399) you report that Dr. Howard Barrows, a neurologist from the new medical school at McMaster University, had recently visited London and had conducted a two-day workshop on the use of simulated patients.

I feel I must inform your readers that Casualties Union has been providing just this service over the past 32 years. The majority of our members simulate injuries for the purpose of training first aiders, but frequently we are asked to provide simulated patients for the purpose of training nurses in their general training and in the nursing of the mentally sick as well as other specialties. To achieve accuracy in the simulation of injuries and disease requires a long period of training in make-up, acting, and staging under the guidance of members of the medical and nursing professions, and it is certainly not a subject to be taken up without good training and without good briefing.

Further details of the work of Casualties Union can always be obtained from our headquarters.-I am, etc.,

ESMOND C. DAwSON Senior Medical Adviser,

1 Grosvenor Crescent 